\title{
Effect of Sports Participation on Academic Achievements among Boys
}

\author{
Kulbir Singh Rana and Anuradha Lehri
}

\begin{abstract}
Aim: To determine effects of Sports Participation on Academic Achievements among males. Material and Method: The study was conducted on 300 male students between 14-17years. Sports Participation questioners and GPA at school were used to determine the Sports Activity participation and Academic achievement respectively. Results: The mean GPA in Team sports, Individual sports and the non-participant group is 3.554, 3.534 and 3.408 respectively and SD value within groups are $0.281,0.281$ and 0.314 respectively. One-way ANOVA shows significant P-value 0.000798.Conclusion: The increased sports participation has significant benefits to students' grades.
\end{abstract}

\author{
Kulbir Singh Rana \\ Ph.D. Student \\ Department of Sports Science \\ Punjabi University, Patiala(Punjab) India \\ E mail: kbsrana@gmail.com \\ Anuradha Lehri \\ Assistant Professor \\ Department of Sports Science \\ Punjabi University, Patiala(Punjab) India
}

Key Words: Mental health, Sports performance, Activity, Cognitive skills, Academic achievements, Grades

DOI: $10.18376 / j e s p / 2018 / v 14 /$ i2/111308

\section{Introduction}

Children's engagement in sports competition is known to contribute to the developmental outcomes for a healthy lifestyle, where children learn about physical, social and cognitive skills (Choi et al, 2014). More broadly, engagement in physical activity is also recognized to contribute a range of positive outcomes, specifically; physical and mental health, social wellbeing, cognitive and academic performance (Bailey et al, 2013). Removing or reducing physical activity classes from the school day may be detrimental to children's physical and mental health as research indicates that school day physical activity is associated with total daily physical activity (Trudeau and Shepard ,2008).High school athletes receive better grades (Darling et al., 2005; Eccles \& Barber, 1999; Eitle\&Eitle, 2002; Silliker\& Quirk, 1997), have higher educational and occupational aspirations (Darling et al., 2005; Marsh \&Kleitman, 2002; Otto \& Alwin, 1977; Sabo et al., 1993), spend more time doing homework (Marsh \&Kleitman, 2002), and have a more positive attitude towards school (Darling et al., 2005; Eccles \& Barber, 1999) than non-athletes, it is not clear if these correlations reflect causal relationships or are driven, in whole or in part, by unmeasured heterogeneity. Students with high participation in school-based physical activities and students with more than 5 bouts per week MVPA were more likely to earn higher grades. (Nelson and Gordon-Larsen,2006). Surprisingly effects of specific sports and selected nutrition on intelligence and academic achievement are somewhat under studied in the developing countries like India. More local and empirical studies need to be conducted to ascertain further details about academic achievement and sporting activity. Hence the relationships between sports participation and academic achievement are studied in this endeavor. 


\section{Material and methods}

The scientific quality of the research findings depends upon research design. It is also known as a blue print of research engineer which tells the reseraher what to do and what not to do while chalking out the steps to be taken in sequential manner for collecting, analyzing the empirical data for the sake of verification of research hypothesis. Hence for selecting a suitable research design for the present investigation, the hypotheses were taken into the consideration. Therefore, for verification of the relation-oriented hypotheses, correlation design considered which includes comparative design also. Contrasted group design and factorial group design used for verification of differential and interactional hypotheses. The present study was conducted on 300 male subjects between age group 14 to 17 years. A detail of the study was explained to each participant and their respective parents and signed consent was taken from them. Screening and evaluation carried out on the basis of inclusion and exclusion criteria. Subjects were further divided into following three groups:

$\begin{array}{ll}\text { Group-1(Team Sports) } & 100 \\ \text { Group-2(Individual Sports) } & 100 \\ \text { Group-3(Non-Participation) } & 100\end{array}$

To assess the type of sports played by the selected subjects were assessed using a child behavior checklist in which students answered questions regarding three favorite extracurricular activities participated by subject which were coded as being team sports (i.e. soccer, cricket, hockey, football etc.) individual sports (i.e. Swimming, biking, skateboard etc.) or no sports if activities listed were not athletics. The academic achievement of the selected subjects was assessed using a teacher report on GPA Scores in school exams.

\section{Results}

The mean GPA in Team sports, Individual sports and the non-participant group is 3.554, 3.534 and 3.408 respectively. And SD value within groups is $0.281,0.281$ and 0.314 respectively. One-way ANOVA shows significant value i.e. P-value 0.000798 .

Table 1. Mean \pm SD of Grade Point Assessment (GPA) of different groups

\begin{tabular}{|l|l|l|l|}
\hline Groups & Means & SD & $\begin{array}{l}\text { ANOVA } \\
\text { (p- value) }\end{array}$ \\
\hline Group-1 (Team Sports) & 3.554 & $\mathbf{0 . 2 8 2}$ & \multirow{2}{*}{$\mathbf{0 . 0 0 0 7 9 8}$} \\
\hline Group-2 (Individual Sports) & $\mathbf{3 . 5 3 4}$ & $\mathbf{0 . 2 8 0}$ & \\
\hline Group-3 (Non-Participation) & $\mathbf{3 . 4 0 8}$ & $\mathbf{0 . 3 1 5}$ & \\
\hline
\end{tabular}

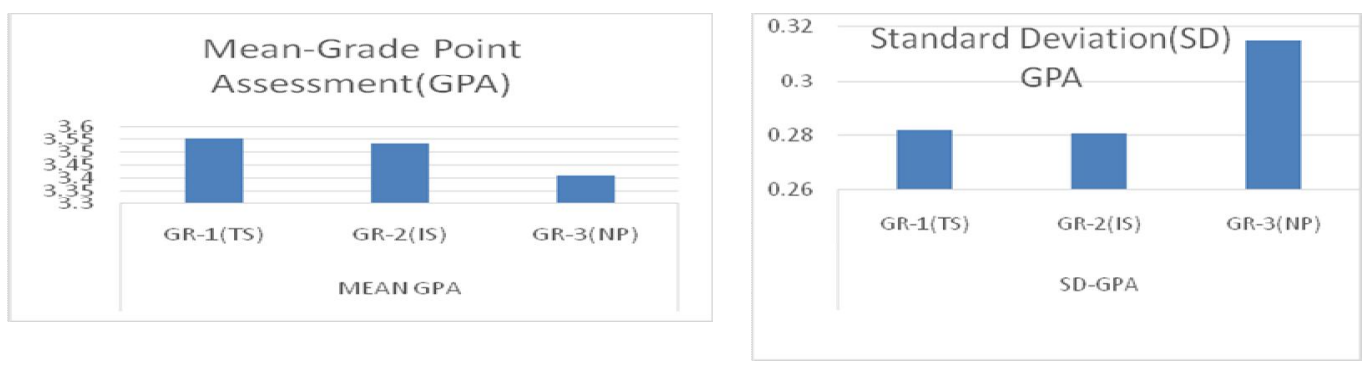

Figure 1. Mean Grade Point Assessment (GPA) of different groups 
Discussion

It can therefore be concluded that participation in sports was not negatively associated with the academic achievement of intermediate students as there was no significant difference found between the grades of sports and non- sports participants. Sports participation was not significantly associated with higher academic grades. Although participation in sports was positively associated with academic achievement for male participants; there was no significant difference between the mean grades of participants i.e. Team and individual sports group.

The majority of prior studies studying the effect of participation in sports on a student's academic achievement have found that students grades are either not affected at all or they are significantly higher when participating in a sport. The results of the current study are consistent with those of other studies as no significant differences were found in student's grades when comparing the mean grades of sports participants with the mean grade of non- sports participants.

The second implication is that students who participate in sports generally do better than students who do not. The support for this statement lies in the Mean GPA of students who reported playing a sport compared with those who reported no sports involvement. Therefore, if students who participate in sports do actually do better academically than non-participants.

The current results should, however, be interpreted with caution because the relationship that is found between the variables is not a causal one. For this reason, the results could be interpreted in two ways, one of which was that participation in sports results in higher mean grades for males. However, it may be that male students that do well at school and obtain high mean grades, and high math's grades, are more likely to participate in sports. Similarly, it may be that students who achieve higher mean grades are more likely to engage in sports more times a week than students that get lower grades.

Similar to other studies, the current study's results found that participating in sports did not negatively impact a student's academic achievement. Furthermore, consistent with previous research (Fox et al., 2010; Linder, 2002) significant positive effects were only found for male sports participants. Additionally, two studies (Chomitz et al., 2009; Stephens and Schaben, 2002) found a significant positive effect on maths grades which was consistent with the current studies results for males. Stephens and Schaben (2002) also found that female sports participants outperformed male sports participants, which was also the case for the current study in English grades.

\section{Conclusion}

Many parents and school personnel alike raise the question of whether participating in a sport has a negative or positive impact of their academic achievement. The results of this study examined this effect and found that sports participation does not negatively impact a student's grades, but in fact students in team sports are more likely to get higher overall grades. Future research is needed in the areas of use of more objective data and demographics, which would increase generalizability. However, these results suggest that increased sports participation is beneficial to students' grades.

\section{Acknowledgement}

I am so grateful of the love, support, and encouragement that all of you have provided me along this journey. This project was executed by me in the Department of Sports Science, Punjabi University Patiala (PB). I would sincerely like to thank all staff members, library staff and my fellow friends for all of their support and encouragement. I would especially like to thank Dr. Anuradha Lehri and Dr. Ashok Kumar for all their input, help, and time. Finally, thank to my entire family member for their continuous support and patience throughout.

\section{References}

Bailey R et a.,. (2013).Physical activity: an underestimated investment in human capital?J Phys Act Health. 2013 Mar;10(3):289-308. 


\section{Journal of Exercise Science \& Physiotherapy Vol. 14 No. 2 (July to December) 2018 \\ ISSN: 0973-2020 (Print) $\quad I_{2}$ OR Impact Factor =6.115 UGC Approved [no.7485] ISSN: 2454-6089 (Online)}

Barber, B.L., Eccles, J.S., \& Stone, M.R. (2001). Whatever happened to the Jock, the Brain, andthe Princes? Young adult pathways linked to adolescent activity involvement and social identity. Journal of Adolescent Research, 16, 429-455.

Choi, H.S., Johnson, B., \& Kim, Y.K. (2014). Children's Development through Sports Competition: Derivative adjustive, Generative, and Maladaptive Approaches. Quest, 66 (2), 191-202.

Chomitz, V. R., Slining, M., M., McGowan, R., J., Mitchell, S., E., Dawson, G., F., \& Hacker, K., A. (2009). Is there a relationship between physical fitness and academic achievement? Positive results from public school children in Northeastern United States. Journal of School Health, 79, 30-37.

Csikszentmihalyi, M. (1991). "An investment theory of creativity and it's development "Commentary. Human Development, 34(1), 32-34.

Darling, N., Caldwell, L.L., \& Smith, R. (2005). Participation in School Based Extracurricular Activities and Adolescent Adjustment. Journal of Leisure Research, 37(1), 51-76.

Eccles, J. S., \& Barber, B. L. (1999). Student council, volunteering, basketball, or marching band: What kind of extracurricular involvement matters? Journal of Adolescent Research, 14, 10-43.

Eitle, T. M., \&Eitle, D., J. (2002). Race, cultural capital, and the educational effects of participation in sports. Sociology of Education, 75, 123-146.

Fox, C. K., Barr-Anderson, D., Neumark-Sztainer, D., \& Wall, M. (2010). Physical activity and sports team participation: Associations with academic outcomes in middle school and high school students. Journal of School Health, 80, 31-37.

Larson, \& J. S. Eccles (Eds.) Organized activities as contexts of development: Extracurricular activities, afterschool and community programs. Mahwah, NJ: Erlbaum.

Lindner, K. J. (2002). The physical activity participation-academic performance relationship revisited: Perceived and actual performance and the effect of banding (academic tracking). Pediatric Exercise Science 14, 155-169.

Luther B. Otto and Duane F. Alwin .Athletics, Aspirations, and AttainmentsSociology of Education, Vol. 50, No. 2 (Apr., 1977), pp. 102-113

Marsh, H.W. and Kleitman, S. (2002) Extracurricular School Activities The Good, the Bad, and the Nonlinear. Harvard Educational Review, 72, 464-515.

Nangle, D.W., \&Erdley, C.A. (Eds.) The role of Friendship in Psychological Adjustment. (pp. 79-92).

Nelson, M.C., \& Gordon-Larsen, P. (2006). Physical Activity and Sedentary Behavior Patterns Are Associated with Selected Adolescent Health Risk Behaviors. Pediatrics, 117(4), 1281-1290.

Silliker, S., \& Quirk, J. (1997). The effect of extracurricular activity participation on the academic performance of male and female high students. The School Counsellor, 44, 288-293.

Stephens, L. J., \&Schaben, L., A. (2002). The effect of interscholastic sports participation on academic achievement of middle level school students. NASSP Bulletin, 86, 34-41.

Trudeau, F., \& Shephard, R. J. (2008). Physical education, school physical activity, school sports and academic performance. International Journal of Behavioral Nutrition and Physical Activity, 5.

Conflict of Interest: None declared 